\section{THU0649 PHENOTYPIC CLUSTERS OF RHEUMATIC/SYSTEMIC IMMUNE-RELATED ADVERSE EVENTS INDUCED BY CANCER IMMUNOTHERAPIES (IMMUNOCANCER INTERNATIONAL REGISTRY)}

Manuel Ramos-Casals ${ }^{1}$, Oliver Lambotte ${ }^{2}$, Marie Kostine ${ }^{3}$, Leonard Calabrese ${ }^{4}$ Maria Suarez-Almazor ${ }^{5}$, Clifton Bingham ${ }^{6}$, Timothy R. Radstake ${ }^{7}$, Chiara Baldini ${ }^{8}$, Thierry Schaeverbeke ${ }^{3}$, Jacques-Eric Gottenberg ${ }^{9}$, Hendrik Schulze-Koops ${ }^{10}$, Jan Leipe ${ }^{11}$, Cassandra Calabrese ${ }^{4}$, Pilar Brito-Zerón ${ }^{12}$, Alejandra FloresChávez $^{13}$, Belchin Kostov ${ }^{14}$, Soledad Retamozo ${ }^{15}$, Gustavo Citera ${ }^{16}$, Eva Aguilar ${ }^{17}$, Michael Richter ${ }^{18}$, Merav Lidar ${ }^{19}$, Benjamin Fisher ${ }^{20}$, JeanMarie Michot ${ }^{2}$, David Liew ${ }^{21}$, Russell Buchanan ${ }^{22}$, Marte Schrumpf-Heiberg ${ }^{23}$, Philippe Guilpain ${ }^{24}$, Debashish Danda ${ }^{25}$, Peter Olsson ${ }^{26}$, Yasunori Suzuki ${ }^{27}$, Saadettin KIlıçkap ${ }^{28}$, Gabriela Hernandez-Molina ${ }^{29}$, Virginia Fernandes Moça Trevisani ${ }^{30}$,Sonja Praprotnik ${ }^{31}$,Ildiko Fanny Horváth ${ }^{32}$,Naoto Azuma ${ }^{33}$, Berkan Armagan ${ }^{28}$, Munther Khamashta ${ }^{34}$, Xavier Mariette ${ }^{35} .{ }^{1} \mathrm{H}$. Clinic, IDIBAPS, Barcelona, Spain; ${ }^{2}$ Bicêtre Hosp, Paris, France; ${ }^{3}$ Centre Hosp Univ, Bordeaux, France; ${ }^{4}$ Cleveland Clinic Foundation, Cleveland, United States of America; ${ }^{5}$ Univ of Texas MD Anderson Cancer Center, Houston, TX, United States of America; ${ }^{6}$ Johns Hopkins Univ, Baltimore, MD, United States of America; ${ }^{7}$ Univ Medical Center Utrecht, Utrecht, Netherlands; ${ }^{8}$ Pisa Univ, Pisa, Italy, ${ }^{9}$ Strasbourg Univ, CNRS, Strasbourg, France; ${ }^{10}$ University of Munich, Munich, Germany; ${ }^{11}$ Univ of Mannheim, Mannheim, Germany; ${ }^{12} \mathrm{H}$. CIMA-Sanitas, Barcelona, Spain; ${ }^{13} \mathrm{Hosp}$ de Especialidades, Mexico, Mexico; ${ }^{14}$ Primary Healthcare Trans Research Group, IDIBAPS, Barcelona, Spain; ${ }^{15}$ INICSA-UNC-CONICET, IUCBC, Cordoba, Argentina; ${ }^{16} I R E P$, Buenos Aires, Argentina; ${ }^{17}$ GEAS-SEMI Spanish Registry, Madrid, Spain; ${ }^{18}$ Mayo School of Graduate Medical Education, Rochester, United States of America; ${ }^{19}$ Sheba Medical Center, Tel Aviv, Israel; ${ }^{20}$ Univ of Birmingham, Birmingham, United Kingdom; ${ }^{21}$ Aus-REISAMIC Registry, Victoria, Australia; ${ }^{22}$ Austin Health, Melbourne, Australia; ${ }^{23}$ Diakonhjemmet Hosp, Oslo, Norway; ${ }^{24}$ Montpellier Univ Hosp, Montpellier, France; ${ }^{25}$ Christian Medical College and Hosp, Vellore, India; ${ }^{26}$ Skåne Univ Hosp Malmö, Malmö, Sweden; ${ }^{27}$ Kanazawa Univ Hosp, Ishikawa, Japan; ${ }^{28}$ Hacettepe Univ, Ankara, Turkey; ${ }^{29}$ INCMNSZ, Mexico, Mexico; ${ }^{30}$ Federal Univ of São Paulo, São Paulo, Brazil; ${ }^{31}$ Univ Medical Centre, Ljubljana, Slovenia; ${ }^{32}$ Debrecen Univ, Debrecen, Hungary, ${ }^{33}$ Hyogo Coll Medicine, Nishinomiya, Japan; ${ }^{34}$ Dubai Hosp, UAE, Dubai, United Arab Emirates; ${ }^{35}$ Université Paris-Sud, Paris, France

Background: The ImmunoCancer International Registry is a Big DataSharing multidisciplinary network focused on the research of the immunerelated adverse events (irAEs) related to cancer immunotherapies (Cls). Objectives: To analyse the worldwide scenario of rheumatic/systemic autoimmune diseases (RSirAEs) associated with the use of Cls during the last 20 years.

Methods: The first objective was to develop a systematic literature review crossing the Cls terms with rheumatic and systemic autoimmune diseases using MedDRAVR 15.0 terms.

Results: RSirAEs were identified in $11 \%$ of 12648 patients with irAEs, including 1435 cases ( $30 \%$ fulfilled criteria for a systemic disease) that were classified in 5 phenotypic clusters:

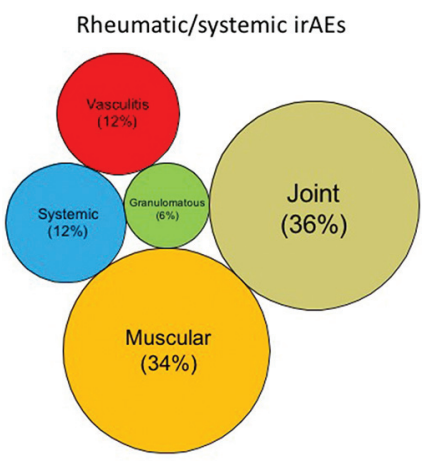

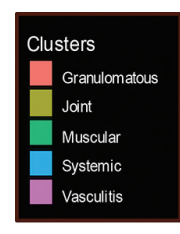
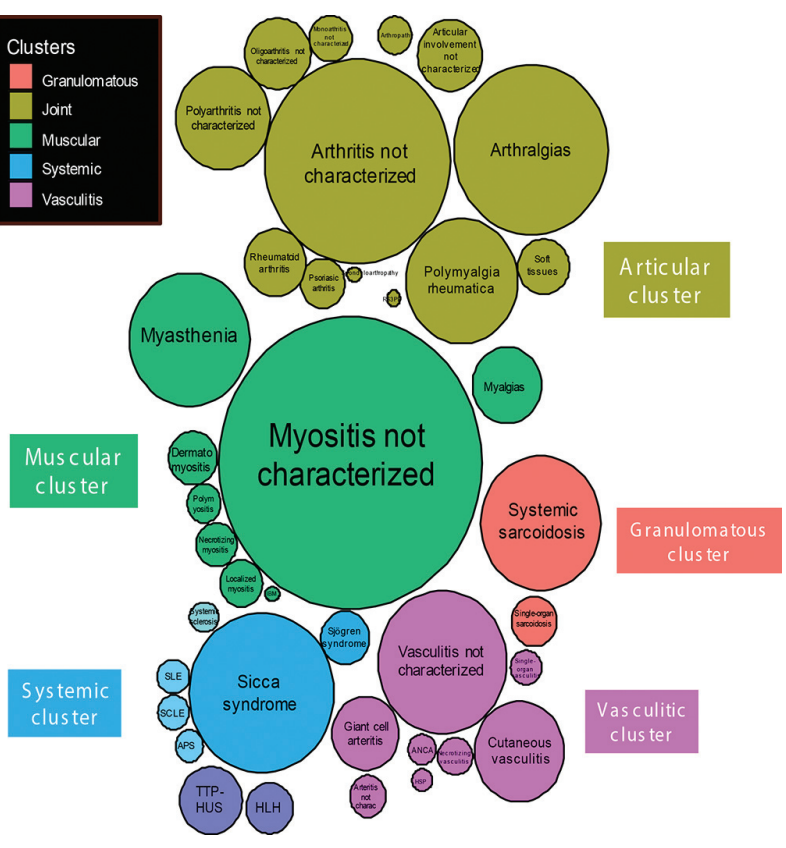

: Non-characterized cases included myositis $(25 \%)$, arthritis (12\%), arthralgias $(8 \%)$, sicca syndrome $(7 \%)$ and vasculitis $(6 \%)$; sarcoidosis $(6 \%)$, myasthenia gravis $(5 \%)$, polymyalgia rheumatica $(4 \%)$, leukocytoclastic vasculitis $(3 \%)$ and giant cell arteritis (2\%) were the most frequent systemic diseases identified:

: In comparison with patients with organ-specific irAEs, RSirAEs were more frequently associated with combined therapies (OR 2.46, $\mathrm{Cl}$ 2.162.81), checkpoint inhibitors -ICis- (OR 4.01 vs TKis, $\mathrm{Cl}$ 3.26-4.92), and PD-1is (OR 2.46 vs CTLA4is, Cl95\% 2.16-2.81)

Conclusion: Rheumatic/systemic irAEs can be divided into 5 phenotypic clusters: articular, muscular, granulomatous, vasculitic and systemic. These findings must be confirmed in real-life patients, and an international datasharing ICIR registry is planned to be launched.

\section{REFERENCES: :}

Disclosure of Interests: : Manuel Ramos-Casals: None declared, Oliver Lambotte: None declared, Marie Kostine: None declared, Leonard Calabrese Consultant for: Bristol-Myers-Squibb, Genentech and Astra-Zeneca., Maria Suarez-Almazor : None declared, Clifton Bingham Grant/research support from: BMS, Consultant for: AbbVie, BMS, Eli Lilly, Genentech/ Roche, Janssen, Pfizer, Sanofi/Regeneron, Timothy R. Radstake: None declared, Chiara Baldini: None declared, Thierry Schaeverbeke: None declared, Jacques-Eric Gottenberg Grant/research support from: BristolMyers Squibb, Grant/research support from: Bristol-Myers Squibb, Consultant for: Bristol-Myers Squibb, Lilly, Pfizer, Sanofi-Genzyme, UCB Pharma, Consultant for: Bristol-Myers Squibb, Eli Lilly, UCB, Sanofi-Genzyme, Pfizer, Hendrik Schulze-Koops Grant/research support from: Novartis, Pfizer, Roche, Consultant for: Abbvie, Actelion, Amgen, AstraZeneca, Biogen International, BMS, Celgene, Chugai, GSK, Hospira, Janssen-Cilag, Leo Pharmaceuticals, Lilly, MSD, Medac, Merck, Novartis, Pfizer, Hexal Sandoz, Sanofi, Roche, UCB, Paid instructor for: Abbvie, Actelion, Amgen, AstraZeneca, Biogen International, BMS, Celgene, Chugai, GSK, Hospira, Janssen-Cilag, Leo Pharmaceuticals, Lilly, MSD, Medac, Merck, Novartis, Pfizer, Hexal Sandoz, Sanofi, Roche, UCB, Speakers bureau: Abbvie, Actelion, Amgen, AstraZeneca, Biogen International, BMS, Celgene, Chugai, GSK, Hospira, Janssen-Cilag, Leo Pharmaceuticals, Lilly, MSD, Medac, Merck, Novartis, Pfizer, Hexal Sandoz, Sanofi, Roche UCB, Jan Leipe Grant/research support from: Novartis, Pfizer; Scientific Support: Novartis, Pfizer, Consultant for: AbbVie, AstraZeneca, BristolMyers Squibb, Celgene, Hospira, Janssen-Cilag, LEO Pharma, Lilly, Novartis, Roche, Sanofi, Speakers bureau: AbbVie, Bristol-Myers Squibb, Celgene, Janssen-Cilag, Lilly, Novartis, MSD, Pfizer, Roche, Sanofi, UCB, cassandra calabrese Speakers bureau: Regeneron/Sanofi, Pilar BritoZerón: None declared, Alejandra Flores-Chávez: None declared, Belchin Kostov: None declared, Soledad Retamozo: None declared, Gustavo Citera: None declared, Eva Aguilar: None declared, Michael Richter: None declared, Merav Lidar: None declared, Benjamin Fisher Consultant for: Novartis, Roche, Medlmmune, Bristol-Myers Squibb, Jean-Marie Michot: None declared, David Liew: None declared, Russell Buchanan: None declared, Marte Schrumpf-Heiberg: None declared, Philippe Guilpain: None 
declared, Debashish Danda: None declared, Peter Olsson: None declared, Yasunori Suzuki: None declared, Saadettin Kılıçkap: None declared, Gabriela Hernandez-Molina: None declared, Virginia Fernandes Moça Trevisani: None declared, Sonja Praprotnik: None declared, Ildiko Fanny Horváth: None declared, Naoto Azuma: None declared, Berkan Armagan: None declared, Munther Khamashta: None declared, Xavier Mariette Grant/research support from: Servier, Consultant for: AstraZeneca, BristolMyers Squibb, GlaxoSmithKline, Janssen, Pfizer, UCB Pharma

DOI: 10.1136/annrheumdis-2019-eular.2870

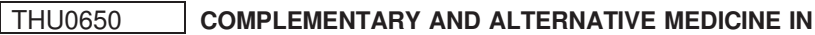 RHEUMATOLOGY: A SURVEY OF ITS USE FOR COMMON RHEUMATOLOGICAL CONDITIONS AMONG MULTI-ETHNIC PATIENTS IN LEICESTERSHIRE}

Chris Sabu Tharakan ${ }^{1}$, Nutchaya Ungcharoen ${ }^{2}$, Jessy Sabu ${ }^{2}$, Arumugam Moorthy ${ }^{2} .{ }^{1}$ University of Nottingham, School of Medicine, Nottingham, United Kingdom; ${ }^{2}$ University Hospitals of Leicester NHS Trust, Rheumatology, Leicester, United Kingdom

Background: The use of complementary and alternative medicine (CAM) is common in patients with chronic disease. ${ }^{1}$ However, the usage of CAMs among patients with rheumatological conditions has been understudied. A significant proportion of primary care trusts are now providing therapies such as acupuncture and osteopathy to some of the 9 million users of CAMs in the United Kingdom (UK). ${ }^{2}$ As the NHS serves a varied patient populace, it is important to appreciate the perceptions and utilisation of CAM amongst multi-ethnic groups.

Objectives:

1. To identify the different types CAMs utilised by Rheumatology patients.

2. To identify Rheumatology patients' views towards the role and use of CAMs in managing their condition(s).

3. To identify locations where patients receive CAM and to determine patient's spending practices.

Methods: A cross-sectional survey on CAMs, and its use for common rheumatological conditions was conducted among multi-ethnic patients in Leicestershire, UK, through convenience sampling. The initial questionnaire was created by a multi-disciplinary input, with a patient-centred focus. Thereafter 10 questionnaires were piloted and revised accordingly. The data subsequently underwent statistical analyses.

Results: A total of 107 patients completed the survey over a 3-month period with a response rate of $90 \%$. Most of the respondents (91.8\%) were over the age of 35 (age range 19 to 78 years, mean age $50.512 .8 \mathrm{SD})$. Among the respondents, $66 \%$ were women and $34 \%$ were men. $72.9 \%$ were of white British or European ethnicity and $20.6 \%$ of South Asian ethnicity (17.8\% Indian and $2.8 \%$ Pakistani). Majority of the patients $(66.4 \%)$ had rheumatoid arthritis (RA), followed by psoriatic arthritis $(11.2 \%)$ and ankylosing spondylitis (4.7\%). The respondent demographics were consistent with known epidemiology of common rheumatological conditions, with a higher prevalence among women than in men (female-to-male ratio of $3: 1$ in $R A$ ).

$31.8 \%$ used CAM for managing symptoms related to their condition(s). Almost half of these respondents $(41.2 \%)$ used CAM products and/or practices daily, with up to $64.7 \%$ spending between $£ 10-£ 100$. The majority of respondents $(82.4 \%)$ received CAM therapy within the UK, followed by India (17.6\%). Commonly used CAM products include: ginger (35.3\%), fish oil supplements (32.4\%), turmeric (32.4\%) and cannabidiol (CBD) oil (23.5\%). The most common CAM therapies were acupuncture (44.1\%), yoga (14.7\%), chiropractice (14.7\%), meditation $(2.9 \%)$ and stretch-fit $(2.9 \%)$. Many respondents $(64.7 \%)$ used more than one product and/or practice. $60 \%$ of the respondents that used CAMs had RA. 9 out of $34(26.5 \%)$ respondents found CAM therapies to be beneficial for their condition(s), with seven (20.6\%) finding it to be useful for pain control/ relief. Up to $17.8 \%$ of all respondents, including those with no prior experience of CAM, perceived potential benefits. However, $65.4 \%$ reported neutral views towards CAM.

Conclusion: In our local multi-ethnic population, it is evident that a notable proportion of patients have utilised CAM to supplement the management of their condition. Healthcare professionals need to be aware of the CAMs available, particularly when informing and treating their patients. Effective communication is required in this area to maintain patient's confidence and safety. Further qualitative research should consider the reasons for the use of CAMs.

\section{REFERENCES:}

1. Metcalfe A, Williams J, McChesney J, Patten S, Jetté N. Use of complementary and alternative medicine by those with a chronic disease and the general population - results of a national population-based survey. BMC Complementary and Alternative Medicine. 2010;10(1)

[2] Verkek R. The Alliance for Natural Health International e-alert number 333 2017.

Disclosure of Interests: Chris Sabu Tharakan: None declared, Nutchaya Ungcharoen: None declared, Jessy Sabu: None declared, Arumugam Moorthy Speakers bureau: Speaker fee from Abbvie, Novartis. DOI: 10.1136/annrheumdis-2019-eular.6493

\section{THU0651 AN INDIVIDUALIZED DECISION-AID FOR DIVERSE WOMEN WITH LUPUS NEPHRITIS (IDEA-WON): A RANDOMIZED CONTROLLED TRIAL}

jasvinder singh ${ }^{1}$, Liana Fraenkel ${ }^{2}$, Candace Green ${ }^{1}$, Graciela S Alarcon ${ }^{1}$, Jennifer Barton ${ }^{3}$, Kenneth Saag ${ }^{1}$, Leslie Hanrahan ${ }^{4}$, Sandra Raymond ${ }^{4}$, Robert Kimberly ${ }^{1}$, Amye Leong ${ }^{5}$, Elyse Reyes ${ }^{6}$, Richard Street ${ }^{7}$, Maria Suarez Almazor $^{8}$, Guy Eakin $^{9}$, Laura Marrow ${ }^{9}$, Charity Morgan ${ }^{1}$, Brennda Caro ${ }^{10}$, Jeffrey Sloan ${ }^{11}$, Bochra Jandali ${ }^{12}$, Salvador Garcia ${ }^{12}$, Jennifer Grossman ${ }^{13}$ Kevin Winthrop ${ }^{3}$,Laura Trupin ${ }^{14}$, Maria Dall'era ${ }^{14}$, Alexa Meara ${ }^{11}$, Tara Rizvi ${ }^{12}$, Winn Chatham ${ }^{1}$, Jinoos Yazdany ${ }^{14}$. ${ }^{1}$ University of Alabama in Birmingham, Birmingham, United States of America; ${ }^{2}$ Yale University, New Haven, CT, United States of America; ${ }^{3}$ Oregon Health Science University, Portland, OR, United States of America; ${ }^{4}$ Lupus Foundation of America, Washington DC, United States of America; ${ }^{5}$ Healthy Motivation Inc., Los Angeles CA, United States of America; ${ }^{6}$ Elyse Reyes Consulting, Los Angeles CA, United States of America; ${ }^{7}$ Texas AandM University, College Station TX, United States of America; ${ }^{8}$ University of Texas MD Anderson Cancer Center, Houston TX, United States of America; ${ }^{9}$ Arthritis Foundation, Atlanta GA, United States of America; ${ }^{10}$ Georgia State University, Atlanta GA, United States of America; ${ }^{11}$ Mayo Clinic School of Medicine, Rochester, MN, United States of America; ${ }^{12}$ Baylor College of Medicine, Houston TX. United States of America; ${ }^{13}$ University of California, Los Angeles CA, United States of America; ${ }^{14}$ Ohio State University, Columbus $\mathrm{OH}$, United States of America

Background: Medication decision-making is challenging in lupus. No validated, effective decision-aids are available to assist patients with medica tion decision-making.

Objectives: Our objective was to assess the effectiveness of an individu alized, culturally-tailored, computerized decision-aid for immunosuppressive medications for lupus nephritis.

Methods: In a multicenter, randomized controlled trial, diverse adult women with lupus nephritis, largely racial/ethnic minorities with low socioeconomic status, were randomized to decision-aid vs. American College of Rheumatology lupus pamphlet (1:1 ratio). Co-primary outcomes were change in decisional conflict and informed choice regarding immunosup pressive medications.

Results: Of 301 randomized women, 47\% were African-American, $26 \%$ were Hispanic, and 15\% White. Mean age (standard deviation [SD]) was 37 (12) years, $57 \%$ had annual income of $<\$ 40,000$, and $36 \%$ had a high-school education or less. Compared to the pamphlet $(n=147)$, participants randomized to the decision-aid $(n=151)$ had: (1) a clinically meaningful and statistically significant larger decrease in decisional conflict 21.8 (standard error [SE], 2.5) vs. 12.7 (SE, 2.0; $\mathrm{p}=0.005$ ); and (2) a clinically meaningful difference in informed choice, statistically non-significant in the main analysis, $41 \%$ vs. $31 \%(p=0.08)$, but significant in sensitivity analysis (net values for immunosuppressives positive [in favor] vs. negative [against]), $50 \%$ vs $35 \%$ ( $p=0.006$ ). Respectively, unresolved decisional conflict post-intervention was significantly lower, $22 \%$ vs. $44 \%$ $(p<0.001)$. Significantly more patients in decision-aid vs. pamphlet group rated information to be excellent for understanding lupus nephritis $(49 \%$ vs. $33 \%)$, risk factors $(43 \%$ vs. $27 \%)$, medication options $(50 \%$ vs. $33 \%$ $p \leq 0.003$ for all); and the ease of use of materials higher $(51 \%$ vs. $38 \%$; $\mathrm{p}=0.006$ )

Conclusion: An individualized decision-aid was effective in reducing decisional conflict for immunosuppressive medications in diverse women with lupus nephritis.

Disclosure of Interests: jasvinder singh Shareholder of: Amarin pharmaceuticals and Viking therapeutics, Consultant for: Crealta/Horizon, Fidia UBM LLC, Medscape, WebMD, the National Institutes of Health and the American College of Rheumatology, Liana Fraenkel: None declared, Candace Green: None declared, Graciela S Alarcon: None declared, Jennifer Barton: None declared, Kenneth Saag Grant/research support from: Amgen, Ironwood/AstraZeneca, Horizon, SOBI, Takeda, Consultant for: Abbvie, Amgen, Ironwood/AstraZeneca, Bayer, Gilead, Horizon, Kowa, Radius, Roche/Genentech, SOBI, Takeda, Teijin, Leslie Hanrahan: None declared, Sandra Raymond: None declared, Robert Kimberly: None 